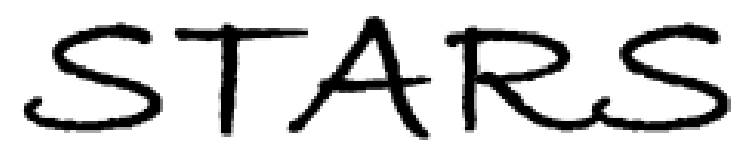

University of Central Florida

STARS

$1-1-2013$

\title{
Grain size softening effect in Al62.5Cu25Fe12.5 nanoquasicrystals
}

N. K. Mukhopadhyay

F. Ali

S. Scudino

M. Samadi Khoshkhoo

M. Stoica

See next page for additional authors

Find similar works at: https://stars.library.ucf.edu/facultybib2010

University of Central Florida Libraries http://library.ucf.edu

This Article is brought to you for free and open access by the Faculty Bibliography at STARS. It has been accepted for inclusion in Faculty Bibliography 2010s by an authorized administrator of STARS. For more information, please contact STARS@ucf.edu.

\section{Recommended Citation}

Mukhopadhyay, N. K.; Ali, F.; Scudino, S.; Khoshkhoo, M. Samadi; Stoica, M.; Srivastava, V. C.; Uhlenwinkel, V.; Vaughan, G.; Suryanarayana, C.; and Eckert, J., "Grain size softening effect in Al62.5Cu25Fe12.5 nanoquasicrystals" (2013). Faculty Bibliography 2010s. 4436.

https://stars.library.ucf.edu/facultybib2010/4436

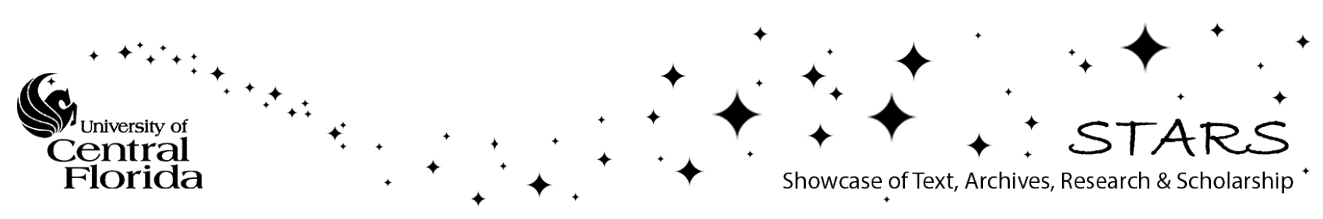




\section{Authors}

N. K. Mukhopadhyay, F. Ali, S. Scudino, M. Samadi Khoshkhoo, M. Stoica, V. C. Srivastava, V. Uhlenwinkel, G. Vaughan, C. Suryanarayana, and J. Eckert 


\section{Grain size softening effect in $\mathrm{Al}_{62.5} \mathrm{Cu}_{25} \mathrm{Fe}_{12.5}$ nanoquasicrystals}

Cite as: Appl. Phys. Lett. 103, 201914 (2013); https://doi.org/10.1063/1.4831737

Submitted: 02 October 2013 . Accepted: 31 October 2013 . Published Online: 15 November 2013

N. K. Mukhopadhyay, F. Ali, S. Scudino, M. Samadi Khoshkhoo, M. Stoica, V. C. Srivastava, V. Uhlenwinkel, G. Vaughan, C. Suryanarayana, and J. Eckert
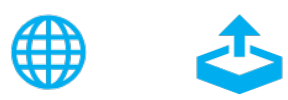

\section{ARTICLES YOU MAY BE INTERESTED IN}

Influence of leaching on surface composition, microstructure, and valence band of single grain icosahedral Al-Cu-Fe quasicrystal

The Journal of Chemical Physics 142, 094703 (2015); https://doi.org/10.1063/1.4913567

Binary $\mathrm{Ni}-\mathrm{Nb}$ bulk metallic glasses

Journal of Applied Physics 99, 026103 (2006); https://doi.org/10.1063/1.2158130

Grain-size dependence of plastic deformation in nanocrystalline $\mathrm{Fe}$

Journal of Applied Physics 93, 9282 (2003); https://doi.org/10.1063/1.1569035

\section{Applied Physics Reviews} Now accepting original research 


\title{
Grain size softening effect in $\mathrm{Al}_{62.5} \mathrm{Cu}_{25} \mathrm{Fe}_{12.5}$ nanoquasicrystals
}

\author{
N. K. Mukhopadhyay, ${ }^{1, a)}$ F. Ali, ${ }^{2, b)}$ S. Scudino, ${ }^{3, c)}$ M. Samadi Khoshkhoo, ${ }^{3, d)}$ M. Stoica, ${ }^{3, e)}$ \\ V. C. Srivastava, ${ }^{4, f)}$ V. Uhlenwinkel, ${ }^{5, g)}$ G. Vaughan, ${ }^{6, h)}$ C. Suryanarayana, ${ }^{7, i)}$ \\ and J. Eckert ${ }^{3,8, j)}$ \\ ${ }^{1}$ Department of Metallurgical Engineering, Indian Institute of Technology (BHU), Varanasi 221 005, India \\ ${ }^{2}$ Pakistan Institute of Engineering \& Applied Science, P.O. Nilore, Islamabad, Pakistan \\ ${ }^{3} I F W$ Dresden, Institut für Komplexe Materialien, Postfach 2701 16, D-01171 Dresden, Germany \\ ${ }^{4}$ Metal Extraction \& Forming Division, National Metallurgical Laboratory, Jamshedpur 831007, India \\ ${ }^{5}$ Institut für Werkstofftechnik, Universität Bremen, Badgasteiner Str. 3, D-28359 Bremen, Germany \\ ${ }^{6}$ European Synchrotron Radiation Facilities ESRF, BP 220, 38043 Grenoble, France \\ ${ }^{7}$ Department of Mechanical and Aerospace Engineering, University of Central Florida, Orlando, \\ Florida 32816-2450, USA \\ ${ }^{8}$ TU Dresden, Institut für Werkstoffwissenschaft, D-01062 Dresden, Germany
}

(Received 2 October 2013; accepted 31 October 2013; published online 15 November 2013)

\begin{abstract}
Inverse Hall-Petch (IHP) behavior in nano-quasicrystalline $\mathrm{Al}_{62.5} \mathrm{Cu}_{25} \mathrm{Fe}_{12.5}$ is reported. Powders with varying grain sizes were produced by mechanical milling of spray-formed quasicrystals. The hardness of the milled powders increased with decreasing grain size down to about $40 \mathrm{~nm}$ and decreased with further refinement, demonstrating the IHP behavior. This critical grain size was found to be larger compared to other metallic nanocrystalline alloys. This IHP behaviour has been attributed to the structural complexity in quasicrystals and to thermally activated shearing events of atoms at the grain boundaries. (C) 2013 AIP Publishing LLC. [http://dx.doi.org/10.1063/1.4831737]
\end{abstract}

Quasicrystals (QCs) are a new class of structurally complex intermetallics that do not exhibit any periodicity but still possess a long-range translational as well as rotational order in the structure, resulting in discrete diffraction patterns with allowed/forbidden rotational symmetries. Among these, the quasicrystalline $\mathrm{Al}-\mathrm{Fe}-\mathrm{Cu}$ alloys have been studied extensively for possible applications such as reinforcements in Al-based composites, catalysis, and coatings (for a review, see Ref. 1). These materials are brittle at room temperature due to the immobility of dislocations. Thus, current efforts are directed to improve the ductility of these materials through grain refinement down to nanometer level by advanced processing techniques. High-energy ball milling is one of the popular methods to produce nanocrystalline ${ }^{2,3}$ and nanocomposite ${ }^{4}$ materials. Prolonged milling at high intensity of Al-Fe-Cu alloys led to disordering of the QC phase forming a $\mathrm{BCC}$ phase. ${ }^{5}$ However, in the present investigation, we have synthesized the nanostructured QC (n-QC) phase by milling the powder at lower intensities.

Strengthening by grain refinement is well-known ${ }^{6}$ and is expressed by the Hall-Petch (HP) relationship, ${ }^{7-12}$

$$
\sigma=\sigma_{0}+k d^{-\frac{1}{2}}
$$

\footnotetext{
a)mukho.nk@gmail.com

b)fahadali62@hotmail.com

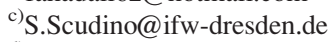

d) m.samadi.khoshkhoo@ifw-dresden.de

e) M.Stoica@ifw-dresden.de

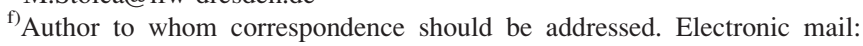
vcsrivas@gmail.com

g)uhl@iwt.uni-bremen.de

h)vaughan@esrf.fr

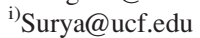

${ }^{\mathrm{j})}$ J.Eckert@ifw-dresden.de
}

where $\sigma_{0}$ is the frictional stress resisting the motion of dislocations, $k$ is the HP slope related to the measure of resistance for the movement of dislocations from one grain to another, and $d$ is the grain size. ${ }^{7-9}$ The HP strengthening has been ascribed to the pile-up of dislocations and their resistance to slip transfer. ${ }^{7-10}$ However, since dislocation activity is almost absent in nanostructured materials, ${ }^{12-14}$ there should be a critical grain size below which the above equation may not be valid (i.e., $k$ may not be positive). Indeed, several reports have shown that, below a critical grain size (typically, 10-30 nm), the HP slope may decrease and even become negative, the so-called inverse Hall-Petch (IHP) behavior. ${ }^{11-23}$ Although supported experimentally, the reasons for the occurrence of the IHP behavior are still controversial, in particular when two-step processes, such as consolidation of milled powders or crystallization of amorphous materials, are used to obtain nanocrystalline materials. The thermal treatments used in the two-step processing are suggested to induce changes in the structure and composition of the grain boundaries as well as densification, stress relief and phase transformations that, in turn, may lead to an "apparent" IHP behavior. ${ }^{13,14,20}$ Thus, it is most desirable to investigate the effect of grain size on the strength of materials in the as-prepared nanocrystalline materials.

Softening by grain refinement has been reported for pure metals and crystalline intermetallic compounds. ${ }^{11,13-29}$ Generally, Coble creep, grain boundary sliding, and grain boundary triple junction activity have been suggested to explain the deformation behavior of nanocrystalline materials. ${ }^{14,22,24}$ Conrad and Narayan ${ }^{25,26}$ have proposed the grain boundary sliding model to explain the above IHP behavior. Recently, Mohamed ${ }^{22}$ suggested that grain boundary sliding could take place by the generation of dislocations at grain boundaries and their movement through the nanograins without causing any pile-up. The stress concentration at grain 
boundaries generates dislocations. Since dislocation movement through the nanograin is extremely difficult, dislocation-assisted grain boundary sliding may be responsible for deformation and consequent grain size softening. Padmanabhan et al. ${ }^{30}$ have developed a phenomenological model, based on the concept that deformation in nanocrystalline materials is basically controlled by atomic scale grain boundary sliding that can account for grain size softening. Chattopadhyay et al. ${ }^{31}$ have advocated that the excess free volume of grain boundary atoms below a critical grain size induces grain boundary softening and accounts for the IHP relationship.

Nanostructured materials are usually described as consisting of two components-grains and the interfaces, the fraction of the latter increasing with a decrease in grain size. The grains could be quasicrystalline ${ }^{27}$ or "glassy," 28 when these materials will be referred to as nano-quasicrystalline alloys and nano-glasses, respectively. Therefore, it will be instructive to see if the IHP behavior is present in nanoquasicrystalline alloys and also to evaluate if the softening behavior in nano-quasicrystals could be explained based on the models available for IHP behavior. Our preliminary results on IHP behavior in $\mathrm{n}-\mathrm{QC}$ were briefly mentioned earlier (cited in Ref. 32). Here, we report a detailed investigation and the analysis on the IHP of n-QC $\mathrm{Al}_{62.5} \mathrm{Cu}_{25} \mathrm{Fe}_{12.5}$ alloy.

The quasicrystalline material produced by spray deposition (see Ref. 33), with the nominal composition of $\mathrm{Al}_{62.5} \mathrm{Cu}_{25} \mathrm{Fe}_{12.5}$ (at.\%), were mechanically milled up to $80 \mathrm{~h}$ at a ball-to-powder mass ratio of 10:1 and milling speed of $100 \mathrm{rpm}$, with interrupted intervals of $15 \mathrm{~min}$ to avoid a strong temperature rise. Structural characterization of powders was performed by X-ray diffraction (XRD) in transmission configuration using a high-energy monochromatic synchrotron beam $(\lambda=0.011249 \mathrm{~nm})$ at European Synchrotron Radiation Facilities (ESRF). The grain size of the powders was evaluated by XRD and by transmission electron microscopy (TEM). Around 200 grains were used for grain size estimation. Microhardness of the as-milled powders was measured using Shimadzu HMV-2000 hardness tester at $5 \mathrm{~g}$ load and $10 \mathrm{~s}$ dwell time. At least 20 measurements were made to calculate the mean hardness value.

The XRD pattern of the starting material $(0 \mathrm{~h})$ shows sharp peaks ascribed to the face centered icosahedral (FCI) QC phase (Figure 1). The absence of additional diffraction peaks implied that the $\mathrm{Al}_{62.5} \mathrm{Cu}_{25} \mathrm{Fe}_{12.5}$ was homogeneous. The XRD patterns of the milled samples display a decrease in peak intensity and broadening of the peaks. The peak broadening increased with increasing milling time.

The grain size (d), evaluated by TEM, is plotted against milling time in Figure 2(a). The size rapidly decreased from $\sim 2 \mu \mathrm{m}$ for $0 \mathrm{~h}$ to about $88 \mathrm{~nm}$ after $1 \mathrm{~h}$ of milling (Figure 2(b)), and to $\sim 24 \mathrm{~nm}$ after milling for $20 \mathrm{~h}$ (Figure 2(c)). For longer milling times $(>20 \mathrm{~h}$ ), additional refinement occurred at a slower rate, reaching the minimum value of $\sim 18 \mathrm{~nm}$ after $80 \mathrm{~h}$ (Figure 2(d)). Figure 3 shows the hardness of the milled powders as a function of $d^{-1 / 2}$. Two distinct behaviors can be observed: a conventional HP behavior for grain size range from 2000 to $40 \mathrm{~nm}$, where the hardness increased from 9.6 to $11.5 \mathrm{GPa}$, and an IHP behavior for grain sizes

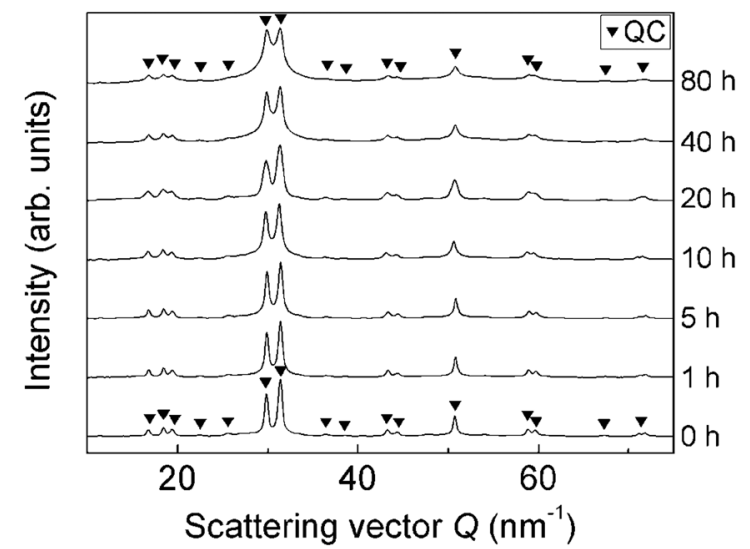

FIG. 1. XRD patterns $(\lambda=0.011249 \mathrm{~nm})$ of the as-deposited $(0 \mathrm{~h})$ and mechanically milled $\mathrm{Al}_{62.5} \mathrm{Cu}_{25} \mathrm{Fe}_{12.5}$ quasicrystalline powders.

less than $40 \mathrm{~nm}$, when the hardness decreased from 11.5 to 8.6 GPa. The HP behavior observed for grain sizes larger than $40 \mathrm{~nm}$ is not linear. The hardness increased from 9.6 to $9.8 \mathrm{GPa}$ with a slope of $k=2.3 \mathrm{GPanm}{ }^{1 / 2}$ for a grain size reduction from 2000 to $100 \mathrm{~nm}$. This is followed by a second stage between 100 and $40 \mathrm{~nm}$, where the hardness increased from 9.8 to $11.5 \mathrm{GPa}$ with a slope $k=30 \pm 4 \mathrm{GPa} \mathrm{nm}^{1 / 2}$. The transition from the HP to IHP behavior occurred at a grain size of $\sim 40 \mathrm{~nm}$, which represents the critical value for grain size in the present quasicrystalline alloy. Below $40 \mathrm{~nm}$, the slope became negative $\left(k=-37 \pm 6 \mathrm{GPa} \mathrm{nm}{ }^{1 / 2}\right)$. The slope of the HP region for sizes $<100 \mathrm{~nm}\left(k=30 \pm 4 \mathrm{GPa} \mathrm{nm}{ }^{1 / 2}\right)$ appears to be identical in magnitude (but negative) to the IHP regime $\left(k=-37 \pm 6 \mathrm{GPa} \mathrm{nm}^{1 / 2}\right)$. It is not clear whether this is just fortuitous or it has some significance. The critical size of $\sim 40 \mathrm{~nm}$ is larger than that typically observed in metallic nanocrystalline alloys $(\sim 20 \mathrm{~nm})$. But, the critical size

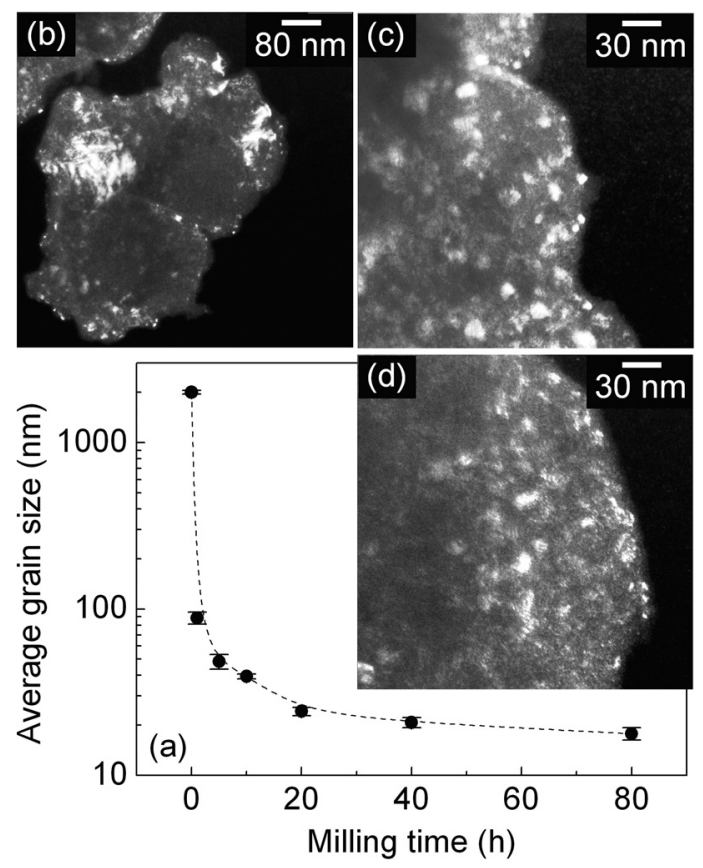

FIG. 2. (a) Plot showing the average grain size of the QC phase as a function of the milling time. TEM micrographs showing the typical grains of the quasicrystals milled for (b) 1 , (c) 20 , and (d) $80 \mathrm{~h}$, when the grain sizes are 88 , 24 , and $18 \mathrm{~nm}$, respectively. 


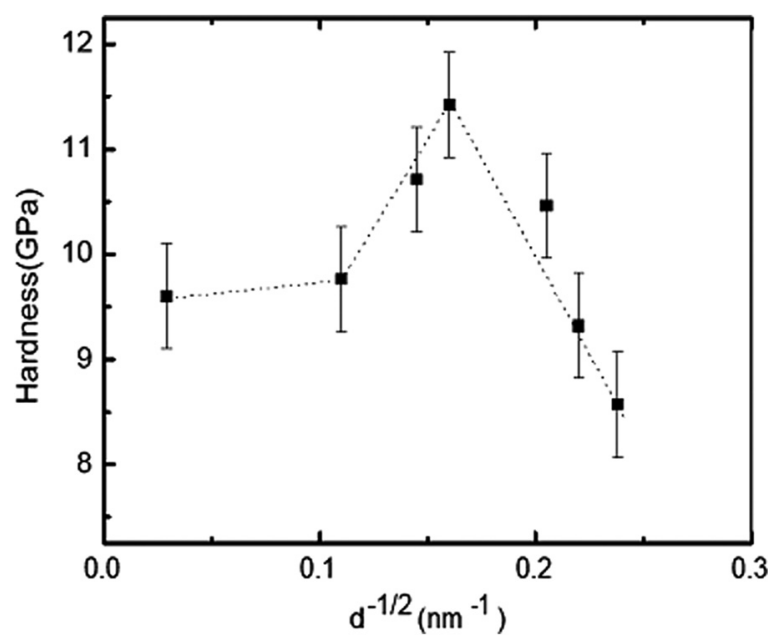

FIG. 3. HP plot of hardness for the mechanically milled $\mathrm{Al}_{62.5} \mathrm{Cu}_{25} \mathrm{Fe}_{12.5}$ quasicrystals showing the transition from HP to IHP behavior at about $40 \mathrm{~nm}$.

was reported to be higher in strong intermetallics; $35 \mathrm{~nm}$ and $63 \mathrm{~nm}$, respectively, for $\mathrm{Nb}_{77} \mathrm{Al}_{23}$ and $\mathrm{NbAl}_{3} .{ }^{25}$ Thus, it appears that the value of the critical grain size is related to the structural complexities and the deformation mechanisms, suggesting that the critical size scales with the structural complexity and strength of the material. The critical sizes for IHP may be similar in structurally complex intermetallics and QCs.

The dislocation-mediated deformation mechanism in micron-sized polycrystals as well as in single crystals of QC phases has been established at moderate to higher temperatures. ${ }^{1,34}$ However, room temperature deformation is mainly controlled by shear band formation. ${ }^{11,35-38}$ Due to the evolution of phason strain during deformation of QCs, the dislocation-assisted deformation is almost absent at room temperature. However, localized shear band formation in micro- and nano-QCs has been observed during room temperature deformation analogous to bulk metallic glasses. ${ }^{39,40}$ Thus, it is argued that in the HP regime, the resistance to shear increases with decreasing grain size due to the resistance offered by chemical ordering. From our XRD data (not presented here), it appears that the order parameter of the ordered FCI phase increases initially with milling time. The order parameter, evaluated by taking the ratio of the intensities of the superlattice reflection (111111) to the fundamental reflection (422222), increases during milling up to $20 \mathrm{~h}$ and then decreases. Thus, it is possible that the asspray-deposited material is not fully ordered. Similar observations of formation of ordered phases on milling have been reported earlier. ${ }^{41,42}$ Because of this ordering as well as the introduced defects, the hardness increases until the grain size reaches $\sim 40 \mathrm{~nm}$. The grain boundaries in nanocrystalline/ quasicrystalline phases are highly disordered resembling the atomic arrangement in amorphous alloys. This causes easy grain boundary sliding and shear band formation leading to softening observed in the IHP regime. Shearing events in grain boundaries become dominant in many nanocrystalline materials in the IHP region. ${ }^{43}$

We examine the above results in the light of two important models for understanding the mechanism(s) responsible for the IHP behavior: (i) dislocation pile-up and (ii) grain boundary shearing model. According to the dislocation pileup model, the critical grain size $d_{c}$ can be predicted by using the equation ${ }^{44}$

$$
\mathrm{d}_{\mathrm{c}} \leq \frac{3 \mathrm{~Gb}}{\pi(1-\nu) \mathrm{H}}
$$

where $\mathrm{G}$ is the shear modulus, $\mathrm{b}$ is the Burgers vector, $\mathrm{H}$ is the hardness, and $\nu$ is Poisson's ratio. However, this model does not suggest the micro-mechanisms by which grain size softening would occur. By substituting the appropriate values for the present material ${ }^{1,11}(\mathrm{G}=74 \mathrm{GPa} ; \nu=0.23 ; \mathrm{H}=8.5 \mathrm{GPa}$; $\mathrm{b}=1 \mathrm{~nm}$ ) in the above equation, $\mathrm{d}_{\mathrm{c}}$ is estimated as $12 \mathrm{~nm}$, a value much lower than the experimental value $\left(\mathrm{d}_{\mathrm{c}} \sim 40 \mathrm{~nm}\right)$. Thus, the model appears to suggest only the minimum lower bound of the grain size but not the grain size when softening exactly will occur. The possible reason for this could be that QC materials do not show dislocation-mediated deformation at room temperature. Hence, the model based on dislocations can give an estimate of grain size where softening must take place analogous to nanocrystalline materials but not for n-QC materials.

The thermally activated shear model proposed by Conrad and Narayan ${ }^{25,26}$ is examined in detail as it appears to be relevant in the present case. The equation derived from their formalism can be expressed as ${ }^{25}$

$$
\dot{\gamma}=\frac{6 \mathrm{~b}^{*} \vartheta_{\mathrm{D}}}{\mathrm{d}} \sinh \left(\frac{\nu^{*} \tau_{e}}{\mathrm{kT}}\right) \exp \left(\frac{\Delta \mathrm{F}}{\mathrm{kT}}\right),
$$

where the grain boundary width is assumed as $3 b^{*}, b^{*}$ is the atomic diameter, $\vartheta_{D}$ is Debye frequency, $\sim 10^{13} \mathrm{~s}^{-1} \cdot \tau_{\mathrm{e}}=\tau$ $-\tau_{\mathrm{c}}=$ effective shear stress, $\tau$ is applied shear stress, $\tau_{\mathrm{c}}$ is a critical stress or back stress, $\tau=\mathrm{H} / 3 \sqrt{ } 3 ; v^{*}$ is activation volume, of the order of $b^{* 3}$, and $\Delta \mathrm{F}$ is the Helmholtz free energy. The above equation can be expressed in two different forms by approximating the pre-exponential stress function contained in sinh function. ${ }^{26}$ Rearranging the above equation in terms of hardness, we get

$$
\begin{gathered}
\mathrm{H}=3 \sqrt{3}\left\{\tau_{\mathrm{c}}+\frac{\mathrm{kT}}{\nu^{*}}\left[\ln \left(\frac{\dot{\gamma}}{3 \mathrm{~b}^{*} \vartheta_{\mathrm{D}}}\right)+\frac{\Delta \mathrm{F}}{\mathrm{kT}}\right]+\frac{\mathrm{kT}}{\nu^{*}}\right\} \ln \mathrm{d}, \\
\mathrm{H}=3 \sqrt{3}\left\{\tau_{\mathrm{c}}+\frac{\mathrm{kT}}{\nu^{*}}\left[\left(\frac{\dot{\gamma}}{3 \mathrm{~b}^{*} \vartheta_{\mathrm{D}}}\right) \exp \frac{\Delta \mathrm{F}}{\mathrm{kT}}\right]\right\} \mathrm{d} .
\end{gathered}
$$

Both the above equations satisfy the IHP behavior and can give rise to the conditions when IHP should be exhibited. Equations (4) and (5) can be used to evaluate the Helmholtz free energy, which should be comparable to the activation energy for grain boundary diffusion. By plotting experimental hardness values against $\ln \mathrm{d}$, we can obtain $v^{*}$ from the slope (Figure 4). This value comes be $\left(1.836 \times 10^{-10}\right)^{3}$ $\mathrm{nm}^{3} \approx\left(1.2 \mathrm{~b}^{*}\right)^{3}$, which seems to be reasonable. From the intercept (assuming $\tau_{\mathrm{c}}=0$ ), $\Delta F$ is calculated to be $46 \mathrm{~kJ} / \mathrm{mol}$. This value appears to be smaller than the normal range of activation energy for grain boundary diffusion. However, when the hardness is plotted against $d$ (Figure 5), according to Eq. (5), $\Delta F$ turns out to be $82 \mathrm{~kJ} / \mathrm{mol}$, which is closer to the activation energy for grain boundary diffusion. ${ }^{26}$ The 


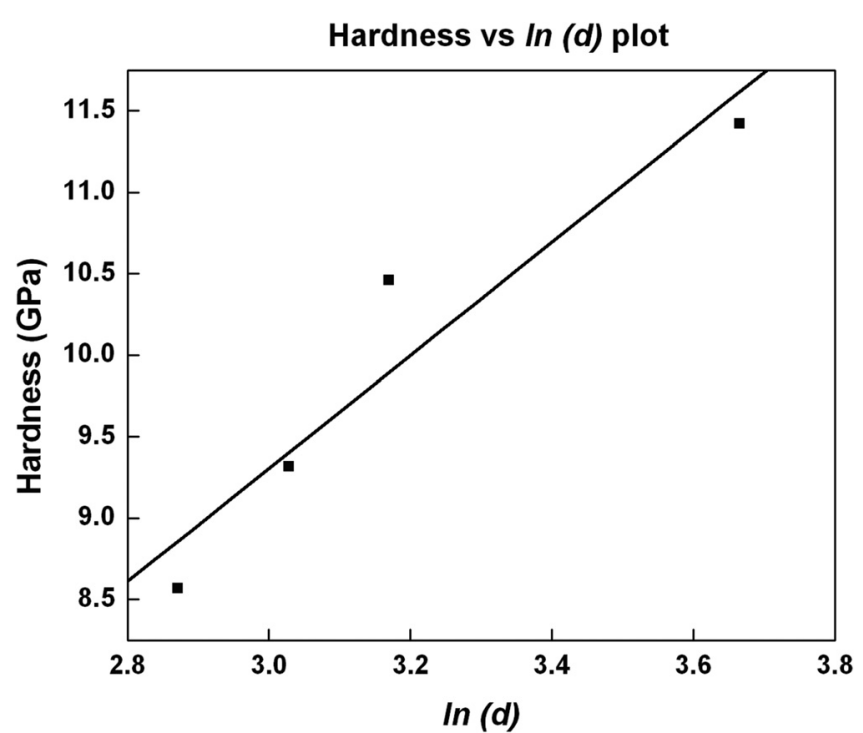

FIG. 4. Plot of Hardness $(\mathrm{H})$ versus $\ln (\mathrm{d})$ following Eq. (4) to evaluate $v^{*}$, activation volume during the process.

reason could be that the approximation of critical shear stress to be zero may be an underestimation. However, for evaluating this value from Eq. (5), this approximation is not needed. Thus, analysis of the hardness data using the above model yields more satisfactory results. In general, diffusion in nanocrystalline materials occurs mostly through grain boundaries and superplastic deformation in nanoceramics is attributed to the enhanced grain boundary diffusion. ${ }^{45}$ That is, nanomaterials showing the HP behavior should not deform by grain boundary-mediated deformation at room temperature, which involves dislocation pile-up. However, below a critical grain size, grain boundary sliding, controlled by different mechanisms, should be operative. Schiotz et $a l .{ }^{46}$ showed by simulation that deformation of nanocrystalline copper is controlled by movement of atoms in the grain boundary. ${ }^{46}$ However, this phenomenon occurs below a critical grain size. In the present case, it appears that the grain boundary shearing event leads to grain boundary

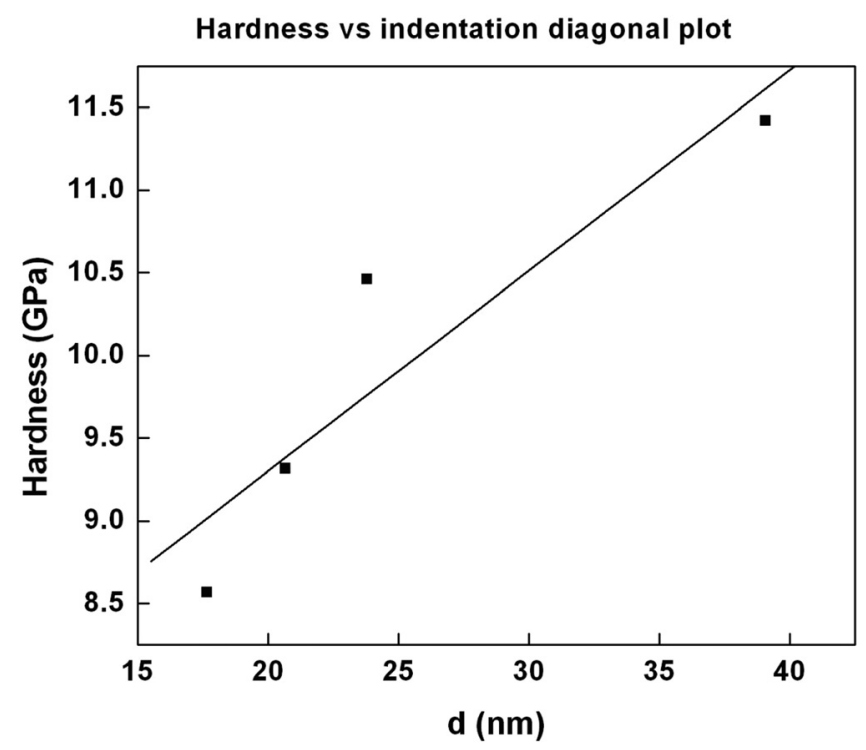

FIG. 5. Plot of Hardness $(\mathrm{H})$ versus d following Eq. (5) to evaluate the Helmholtz free energy for grain boundary shearing. sliding and deformation proceeds through softening mechanisms rather than hardening.

The IHP behavior has been observed in nano-QC materials, which has not been reported earlier. Since one can have nanocrystals, nano-quasicrystals and nano-glasses, and the IHP behavior is observed in nanocrystals and now in nanoquasicrystals, one should observe the IHP phenomenon in nano-glasses as well. This speculation is based on the fact that grain-boundary-mediated deformation processes can also occur in nano-glasses, where the interfacial component is perhaps more disordered than the nano-glassy "grains."

In conclusion, both the HP and IHP behaviors are experimentally established in the present study for an $\mathrm{Al}_{62.5} \mathrm{Cu}_{25} \mathrm{Fe}_{12.5}$ nanoquasicrystalline alloy. The initial enhancement of hardness with a decrease in grain size could be attributed to structural ordering and the defects introduced during milling, which eventually develop the resistance for localized shearing of atoms. The critical grain size of $40 \mathrm{~nm}$, noted to be more than that reported in nanocrystalline alloys, can be attributed to the structural complexities and grain boundary shear mechanisms. The dislocation pile-up model was found to give a very low value of grain size, whereas the grain boundary shearing model appears to be more appropriate for explaining the softening behavior. The activation volume $\left(6.185 \times 10^{-30} \mathrm{~m}^{3} \approx\left(1.2 \mathrm{~b}^{*}\right)^{3}\right)$ and the Helmholtz free energy $(82 \mathrm{~kJ} / \mathrm{mol})$ for causing the grain boundary diffusion appear to be reasonable. Thus, it can be understood that below the critical grain size, thermally activated shearing of atoms at grain boundaries leads to the macroscopic shear and causes grain boundary sliding and are responsible for the observed softening related to IHP of nano-QC phases in Al-Fe-Cu alloys.

F. Ali acknowledges the PIEAS for financial support. N. K. Mukhopadhyay and V. C. Srivastava thankfully acknowledge the support of Alexander von Humboldt Foundation $(\mathrm{AvH})$ for pursuing the collaborative research work.

${ }^{1}$ E. Huttunen-Saarivirta, J. Alloys Compd. 363, 150 (2004).

${ }^{2}$ C. Suryanarayana, Prog. Mater. Sci. 46, 1 (2001).

${ }^{3}$ C. Suryanarayana, Mechanical Alloying and Milling (Marcel Dekker, New York, 2004).

${ }^{4}$ C. Suryanarayana and N. Al-Aqeeli, Prog. Mater. Sci. 58, 383 (2013).

${ }^{5}$ N. K. Mukhopadhyay, F. Ali, V. C. Srivastava, T. P. Yadav, M. Sakaliyska, K. B. Surreddi, S. Scudino, V. Uhlenwinkel, and J. Eckert, Philos. Mag. 91, 2482 (2011).

${ }^{6}$ W. D. Callister and D. G. Rethwisch, Materials Science and Engineering: An Introduction, 8th ed. (John Wiley \& Sons, New York, 2010).

${ }^{7}$ E. O. Hall, Proc. Phys. Soc. London 64, 747 (1951).

${ }^{8}$ N. J. Petch, J. Iron Steel Inst., London 174, 25 (1953).

${ }^{9}$ R. W. Armstrong, in Yield, Flow and Fracture of Polycrystals, edited by T. N. Baker (Applied Science Publishers, London, 1983).

${ }^{10}$ A. Lasalmonie and J. L. Strudel, J. Mater. Sci. 21, 1837 (1986).

${ }^{11}$ N. K. Mukhopadhyay and P. Paufler, Int. Mater. Rev. 51, 209 (2006).

${ }^{12}$ H. W. Song, S. R. Guo, and Z. Q. Hu, Nanostruct. Mater. 11, 203 (1999).

${ }^{13}$ C. C. Koch and J. Narayan, Inverse Hall-Petch effect - Fact or Artifact?, edited by D. Farkas, H. Kung, M. Mayo, H. Van Swygenhoven, and J. Weertman (Mater. Res. Soc. Symp. Proc., 2001), Vol. 634, p. B5.1.1.

${ }^{14}$ C. Suryanarayana, Int. Mater. Rev. 40, 41 (1995).

${ }^{15}$ C. S. Pande and K. P. Cooper, Prog. Mater. Sci. 54, 689 (2009).

${ }^{16}$ H. Chang, C. J. Altstetter, and R. S. Averback, J. Mater. Res. 7, 2962 (1992).

${ }^{17}$ U. Erb, Nanostruct. Mater. 6, 533 (1995).

${ }^{18}$ S. Y. Chang and T. K. Chang, J. Appl. Phys. 101, 033507 (2007).

${ }^{19}$ D. Jang and M. Atzmon, J. Appl. Phys. 93, 9282 (2003). 
${ }^{20}$ R. W. Siegel, Mater. Sci. Forum 235-238, 851 (1997).

${ }^{21}$ C. Suryanarayana, D. Mukhopadhyaya, S. N. Patankar, and F. H. Froes, J. Mater. Res. 7, 2114 (1992).

${ }^{22}$ F. A. Mohamed, Metall. Mater. Trans. A 38, 340 (2007).

${ }^{23}$ C. Suryanarayana, Mater. Today 15, 486 (2012).

${ }^{24}$ M. A. Meyers, A. Mishra, and D. J. Benson, Prog. Mater. Sci. 51, 427 (2006).

${ }^{25}$ H. Conrad and J. Narayan, Scr. Mater. 42, 1025 (2000).

${ }^{26}$ H. Conrad and J. Narayan, Appl. Phys. Lett. 81, 02241 (2002).

${ }^{27}$ C. Suryanarayana and C. C. Koch, Hyperfine Interact. 130, 5 (2000).

${ }^{28}$ H. Gleiter, Prog. Mater. Sci. 33, 223 (1989).

${ }^{29}$ A. H. Chokshi, A. Rosen, J. Karch, and H. Gleiter, Scr. Metall. 23, 1679 (1989).

${ }^{30}$ K. A. Padmanabhan, G. P. Dinda, H. Hahn, and H. Gleiter, Mater. Sci. Eng., A 452-453, 462 (2007).

${ }^{31}$ P. P. Chattopadhyay, S. K. Pabi, and I. Manna, Z. Metallkd. 91, 1049 (2000).

${ }^{32}$ N. K. Mukhopadhyay and T. P. Yadav, Isr. J. Chem. 51, 1185 (2011).

${ }^{33}$ V. C. Srivastava, V. Uhlenwinkel, A. Schulz, H. W. Zoch, N. K. Mukhopadhyay, and S. G. Chowdhury, Z. Kristallogr. 223, 711 (2008).

${ }^{34}$ M. Feuerbacher, C. Metzmacher, M. Wollgarten, K. Urban, B. Baufeld, M. Bartsch, and U. Messerschmidt, Mater. Sci. Eng., A 226-228, 943 (1997).
${ }^{35}$ V. Azhazha, S. Dub, G. Khadzhay, B. Merisov, S. Malkin, and A. Pugachov, Philos. Mag. 84, 983 (2004).

${ }^{36}$ N. K. Mukhopadhyay, A. Belger, P. Paufler, and P. Gille, Philos. Mag. 86, 999 (2006).

${ }^{37}$ N. K. Mukhopadhyay, A. Belger, P. Paufler, E. Uhrig, S. Bruhne, and W. Assmus, J. Alloys Compd. 466, 160 (2008).

${ }^{38}$ M. Abu Shaz, N. K. Mukhopadhyay, R. K. Mandal, and O. N. Srivastava, J. Alloys Compd. 342, 49 (2002).

${ }^{39}$ N. K. Mukhopadhyay, A. Belger, P. Paufler, and D. H. Kim, Mater. Sci. Eng., A 449-451, 954 (2007).

${ }^{40} \mathrm{C}$. Suryanarayana and A. Inoue, Bulk Metallic Glasses (CRC Press, Boca Raton, FL, 2011).

${ }^{41}$ C. Suryanarayana, E. Zhou, Z. Peng, and F. H. Froes, Scr. Metall. Mater. 30, 781 (1994).

${ }^{42}$ C. Suryanarayana, W. Li, and F. H. Froes, Scr. Metall. Mater. 31, 1465 (1994).

${ }^{43}$ H. Alves, M. Ferreira, U. Koster, and B. Muller, Mater. Sci. Forum 225-227, 769 (1996).

${ }^{44}$ T. G. Nieh and J. Wadsworth, Scr. Metall. Mater. 25, 955 (1991).

${ }^{45}$ J. Karch, R. Birringer, and H. Gleiter, Nature 330, 556 (1987).

${ }^{46}$ J. Schiotz, F. D. Di Tolla, and K. W. Jacobsen, Nature 391, 561 (1998). 